\title{
Imaginarios y planificación urbana. Encuentros y desencuentros entre los habitantes del oriente de Cali - Colombia y el proceso de ordenamiento territorial ${ }^{1}$
}

\section{Imaginaries and urban planning. Encounters and disagreements between the inhabitants of the East of Cali - Colombia and the process of territorial planning}

\section{Resumen}

El presente escrito da cuenta de los imaginarios sobre planificación urbana que tienen los habitantes del oriente de Cali, una zona caracterizada por la segregación socioespacial, el poblamiento informal, altos índices de vulnerabilidad social y necesidades básicas insatisfechas. El objetivo se centró en establecer la relación entre las imágenes que crean sobre el espacio los habitantes de esta zona de la ciudad con el proceso de planificación. Las fuentes de información que se utilizan en el texto son producto de una metodología cualitativa que incluyó técnicas como las entrevistas semiestructuradas, la observación participante y la revisión documental. El análisis permitió identificar que, a pesar de la participación en el nivel informativo de algunos de los habitantes en la implementación del ordenamiento, esta relación no implica ser tenidos en cuenta en los cambios socioespaciales de la ciudad.

Palabras clave: Planificación urbana, segregación socioespacial, participación comunitaria.

1. Este artículo es producto del proyecto "Imaginarios sobre planificación urbana. Una mirada desde los habitantes del oriente a propósito de Cali Distrito Especial", parte de la quinta convocatoria de los proyectos de investigación de la Fundación Universitaria Católica Lumen Gentium.

2. Trabajadora Social, Especialista en Procesos de Intervención Social y Magíster en Estudios Sociales y Políticos. Docente de la Fundación Universitaria Católica Lumen Gentium, Cali, Colombia. Grupo de investigación Lumen Humanitas. Correo electrónico: vladino@unicatolica.edu.co. Orcid: https:// orcid.org/0000-0003-3181-427X 


\section{Abstract}

This writing gives an account of the imaginary about urban planning that the inhabitants of the East of Cali have, an area characterized by socio-spatial segregation, informal settlement, high rates of social vulnerability and unsatisfied basic needs. The objective focused on establishing the relationship between the images that the inhabitants of this area of the city create about the space with the planning process. The sources of information used in the text are the product of a qualitative methodology that included techniques such as semi-structured interviews, participant observation and documentary review. The analysis allowed to identify that, despite the participation in the information level of some of the inhabitants in the implementation of the ordinance, this relationship does not imply being taken into account in the socio-spatial changes of the city.

Keywords: Urban planning, socio-spatial segregation, community participation.

\section{Introducción}

Desde su fundación, la ciudad de Cali ha tenido oleadas de crecimiento debido a su condición de cruce de caminos y recepción de población de diversos lugares del país, por lo cual la expansión de su zona habitable ha sido acelerada y sin planificación previa, y los procesos de ordenamiento del territorio se han ido adecuando posterior a los procesos de toma de tierras por vías informales e ilegales. Una realidad que se ha compartido con el resto de las ciudades colombianas, y también con la expansión urbana en Latinoamérica. Al carecer de un proceso de expansión planificado y juicioso, la ciudad ha tenido un crecimiento desordenado que no han logrado resolver con los planes de desarrollo, con los planes de ordenamiento territorial (POT) ni con los demás marcos normativos, los cuales se han quedado en trámites administrativos, más allá de su ejecución.

Lo anterior genera incertidumbres en varios sectores sociales, académicos y en las comunidades organizadas, quienes desean participar de la socialización de la reforma territorial, por lo cual es importante investigar sobre los imaginarios que tienen los habitantes del oriente de la ciudad sobre la planificación urbana y la manera en que son tenidos en cuenta por parte de la administración que formula y ejecuta proyectos de ordenamiento territorial. De igual forma, contribuir con la discusión sobre los territorios de borde, sus formas particulares de habitar la ciudad y la necesidad de sus pobladores por ser escuchados e incluidos en los nuevos proyectos de planificación.

Esta mirada es un aporte a la discusión académica sobre la emergencia de fenómenos periurbanos en la continua expansión de la ciudad, que también sirve de referencia a las entidades gubernamentales y demás actores participantes del proceso de planificación urbana, dado que son estas zonas las que más demandan atención frente a la vulnerabilidad social, y tienen un alto índice de necesidades insatisfechas y baja calidad de vida, que hacen parte de las problemáticas que deben atenderse desde las políticas sociales. Sobre todo, en una ciudad como Cali donde la movilidad social y la integración es muy baja, según lo refiere Vivas (2013), quien además presenta las zonas de oriente y ladera como zonas con "asentamientos informales, dificultades de acceso a los mercados formales de trabajo, bajos niveles de calidad de vida, altas tasas de subutilización de la mano de obra y restricciones en la provisión de bienes públicos locales de buena calidad" (p. 146) y bajo acceso a derechos fundamentales como educación y salud. 
El estudio fue de tipo descriptivo-interpretativo, y el método elegido fue el cualitativo, el cual tuvo por objetivo captar la realidad a partir de la percepción del sujeto, recuperando la subjetividad y dándoles protagonismo, por lo que también parte de una mirada holística (perspectiva de totalidad), interactiva y reflexiva (implicación con el sujeto de estudio), y no impone visiones previas, es abierta, humanista y rigurosa (Sandoval como se citó en Carvajal, 2006).

La investigación buscó construir conocimiento a partir de los sujetos; es decir que el interés se centró en las experiencias, significados, símbolos, percepciones y demás elementos que se juegan en la interacción de los actores inmersos en un contexto específico y su manera de interpretar el mundo. El análisis fue de tipo interdisciplinar, tomando herramientas como la entrevista semiestructurada, la observación participante y la revisión documental, con las cuales se pudo analizar el desarrollo de la planeación en la ciudad en las últimas décadas, desde la perspectiva institucional y de las comunidades.

La población escogida fueron los habitantes del oriente de la ciudad, donde se encuentran informantes claves, conocidos con anterioridad por el equipo investigador; los docentes y los semilleros de investigación del programa de Trabajo Social, además de la cercanía que se tiene con los líderes, organizaciones comunitarias de base, entre otros. Luego de la recolección de los datos en el trabajo de campo, se continuó con el procesamiento de la información y la categorización con base en las dimensiones teóricas previas y el contraste con datos emergentes. Hasta el mes de marzo de 2020 se realizaron 20 entrevistas semiestructuras con los informantes claves de los barrios Puertas del Sol, Valle Grande, Líderes, Potrero Grande, Marroquín y Compartir. El tema de la pandemia dificultó la realización de grupos focales con apoyo en cartografía social, y revisión de archivo, que también estaban previstas.

Por lo anterior, este tema de investigación aporta al fortalecimiento de los estudios urbanos y su relación con el quehacer profesional, como parte de la exploración que se viene haciendo de temas de ciudad, recorriendo sus calles y conociendo sus diversas problemáticas, en donde además se transversalice la intervención social y el quehacer de los trabajadores sociales. También es una forma de articular el programa académico de Trabajo Social con la realidad de una zona como el oriente, donde no solo se concentra la mayoría de la intervención estatal, sino donde viven muchos de los estudiantes y donde la sede Compartir de Unicatólica pretende tener impacto y proyección social.

\section{Los imaginarios urbanos y la planificación: breve mirada a sus antecedentes}

Los imaginarios han sido una línea de investigación de los estudios urbanos que se han desarrollado en los últimos años, y a propósito de las reflexiones de este estudio, se hizo un rastreo de las investigaciones realizadas sobre esa categoría desde los habitantes de las periferias, junto con la dimensión sobre la planificación urbana. Uno de estos estudios es el de "Los imaginarios urbanos: de la teoría y los aterrizajes en los estudios urbanos", de Daniel Hiernaux (2007), el cual es un artículo de reflexión y análisis documental. Se basa en la revisión de archivos, autores y teorías que hablan acerca del tema de imaginarios e intenta abordar el concepto desde una construcción genealógica e histórica, para comprender los diversos matices del concepto y sus usos. Se retoman principalmente los postulados del autor Gilbert Durand. 
Hiernaux habla de cómo los imaginarios hacen parte de la subjetividad individual y colectiva, influencian en la construcción de los pensamientos y en las acciones de los seres humanos. El espacio es el lugar de la imaginación, y por eso una de las formas de captar y entender la creación y construcción del imaginario en un espacio es la exposición directa del sujeto al espacio; puede ser, por ejemplo, a través de imágenes sobre este (reminiscencia visual). Los imaginarios urbanos hacen parte de esa construcción histórica y conjunta de sus pobladores y de cómo entienden, perciben y comprenden cada uno de los espacios de la ciudad (edificios, plazas, monumentos, avenidas, etc.), y hacen parte de la construcción totalizadora de la realidad o de la sociedad y de lo que en ella emerge.

Otro estudio es “Diálogo con Néstor García Canclini. ¿Qué son los imaginarios y cómo actúan en la ciudad?", entrevista realizada por Alicia Lindón (2007) a Néstor García Canclini, en la cual se presenta a la encuesta como herramienta indispensable para abordar el tema de los imaginarios urbanos, tanto en el método cuantitativo como cualitativo. Que se puede combinar con historias de vida, entrevistas en profundidad, observaciones etnográficas. En esos estudios se debe tener en cuenta el papel de las telecomunicaciones y la tecnología, que pueden hacer que los resultados de la investigación se vean modificados, ya sea por falta de acceso o por un constante acceso. Para cada herramienta escogida se debe tener en cuenta el tamaño de la ciudad, para ver la pertinencia de los métodos escogidos.

Es esencial analizar el contexto en el cual surgen los imaginarios, contexto del cual surgen conocimientos. De las visiones totalizadoras, los imaginarios cumplen un rol de complementar los huecos o fracturas de lo que no se llega a conocer o comprender, por eso cobran relevancia conceptos como la intersubjetividad, que alude a la existencia de sujetos que se conciben como individuales pero constituidos socialmente, o la interculturalidad, que hace referencia a los cruces entre culturas. Por ende, la ciudad como objeto de investigación es heterogénea, compleja, no hay localizaciones absolutas. Dentro de una misma ciudad se puede encontrar tanta diversidad, que cada espacio, subregión, comuna, etc., puede llegar a ser muy diferente del otro.

Por otra parte, se encuentra la investigación "Diseño de espacios urbanos desde el imaginario y la participación del ciudadano" de Mary Johana Hernández (2015), que tuvo como objetivo "buscar a partir de la participación de un gran número de actores, gestionar y motivar iniciativas ciudadanas para activar y recuperar un espacio dentro de la localidad que se encuentra en desuso y que tiene un potencial de transformación" (p. 93). La movilización ciudadana actual ha logrado cambiar esta lógica de la administración pública, donde el/la ciudadano/a no solo se informa, sino que participa hasta el punto de involucrarse en el diseño del proyecto y ser parte activa de la gestión y ejecución de este.

El urbanismo participativo puede ser una "solución" o respuesta ante la falta de participación ciudadana en los proyectos urbanos, para que deje de ser un mero requisito de la administración pública y realmente se convierta en espacio de reflexión, conciliación y transformación de la ciudad. Para este tipo de procesos, es necesario tener una metodología participativa de la comunidad. Es indispensable mantener el interés y la atención de las personas participantes del proceso, para que la asistencia sea permanente.

La investigación "De los imaginarios colectivos a la apropiación del territorio: un recorrido conceptual", de Andrea Bibiana 
Reyes-Guarnizo (2014), es un artículo sobre resultados de investigación que se basa en exponer principalmente su marco teórico y conceptual. Como reflexión, si es a partir de las imágenes que las personas comienzan a formar o construir una idea o representación sobre alguna cosa 0 en este caso sobre un espacio, son muy relevantes las estrategias de las telecomunicaciones, pues su interacción con la población se hace a través de lo visual y las imágenes, cuestión que influye mucho en cómo percibimos el mundo que nos rodea, guiado por estas imágenes que nos dan, por ejemplo, en los noticieros.

Es preciso conceptualizar qué se entiende por territorio y la apropiación de este por parte de la población, dado que

como apropiación del territorio es posible considerar el proceso por el cual el espacio se convierte en lugar (espacio simbólico, cargado de significados compartidos por diferentes grupos sociales) a partir del cual se desarrollan aspectos de la identidad relacionados con la permanencia, la seguridad y la satisfacción, derivados precisamente de la necesidad de permanecer cerca o en el lugar. (Reyes-Guarnizo, 2014, p. 11)

Por otra parte, frente al tema del crecimiento urbano en Cali y su planificación aparece el estudio de Ciudad desbordada. Asentamientos informales en Santiago de Cali, Colombia, libro de los autores Hernando Uribe Castro, Germán Ayala Osorio y Carmen Jimena Holguín (2017), quienes presentan categorías como la exclusión social y la informalidad para explicar el crecimiento de Cali, tomando como casos de referencia Samanes del Cauca y el corregimiento de Navarro. Este libro aporta varios elementos para el contexto que se va a trabajar de la investigación y para la delimitación del problema, en la medida que describe parte del crecimiento periférico de Cali como un proceso informal; es decir, destaca la participación de la iniciativa de los habitantes junto con los funcionarios e instituciones del gobierno. Además, se centra en la zona oriente de la ciudad, que es un primer espacio de delimitación que se está pensando para la investigación.

De igual forma destaca el estudio de Ángela María Franco (2020) con su tesis "The production or marginality. Paradoxes of urban planning and housing policies en Cali, Colombia", quien entrelaza la historia de la ciudad con la aparición de espacios de exclusión social y vulnerabilidad, situaciones que se convierten en detonantes para que el concepto emerja en la academia latinoamericana en los años sesenta y setenta, a la vez que aparecen políticas públicas y programas internacionales para intervenir esas problemáticas. La autora plantea que los estudios contemporáneos sugieren que ya no se debe hablar de ese término sino de pobreza, pero ella insiste en que la marginalidad todavía existe y se expresa en múltiples formas.

Aunque Franco (2020) parte de los casos de Llano Verde, en la comuna 15, y 5 asentamientos informales de la comuna 18 de Cali, trasciende una mirada tradicional de la marginalidad desde la sociología, la historia o la antropología, y combina el análisis socioespacial, una mirada crítica de las políticas de planificación y las acciones gubernamentales, ofreciendo aportes para pensar futuras políticas sociales que superen la pobreza urbana en varios sectores de la ciudad y el país. Este aporte se puede contrastar con la investigación sobre "Crecimiento urbano y planificación territorial en la ciudad de Cali. Evolución 1990-2010" de Ana Mercedes Ocampo (2017), quien también plantea una revisión histórica de la planificación territorial en comparación con las condiciones sociales del crecimiento urbano en Latinoamérica y las particularidades que tiene para 
una ciudad como Cali donde es fuerte la violencia, que va integrando aspectos no solo espaciales en la densificación de la ciudad, sino también de exclusión y segregación.

Por su parte, en la tesis sobre "Orientaciones de planificación urbana para la integración urbanística y el manejo de la segregación socioespacial de Cali", Daniel Andrés García (2015) analiza las deficiencias que han existido en materia de políticas públicas sociales en la ciudad, y su relación con situaciones de vulnerabilidad y el crecimiento urbano no planificado e informal de Cali, especialmente en las zonas de ladera y el oriente de la ciudad. Señala que estos problemas tienen unas raíces históricas que han guiado el crecimiento, como el paso del ferrocarril, el ensanchamiento de la ciudad tras la desecación de los humedales al costado oriental, y algunos desarrollos a partir de la política pública. Este estudio incorpora un análisis institucional de la planificación, describiendo que desde los documentos donde se orienta el ordenamiento urbano hay una deficiencia para garantizar la inclusión de ciertos sectores, y en últimas las zonas de crecimiento irregular terminan siendo excluidas y aisladas de la dinámica integral de la ciudad, lo cual permite pensar, para la investigación, las consecuencias del proceso y el sentido y orientación ambivalente que ha tenido el uso y adecuación de espacios en Cali.

\section{Referentes teóricos del crecimiento de las ciudades y su planificación}

El proceso de urbanización tiene dos perspectivas para su conceptualización: una que la ve desde la dimensión y densidad poblacional, y otra que la ve desde la cultura urbana, centrada en los valores y comportamientos (Susser, 2001). Se sugiere tener en cuenta ambas para entender el proceso de urbanización, pues lo urbano tiene que ver con la "forma particular de ocupación del espacio por una población, o sea, la aglomeración resultante de una fuerte concentración y de una densidad relativamente elevada, que tendría, como correlato previsible, una diferenciación funcional y social cada vez mayor" (Susser, 2001, p. 41).

Pero esa forma particular de asentarse en un lugar va a estar asociada al excedente que deja la producción de la tierra, al tipo de producción capitalista, como lo señala Castells (como se citó en Susser, 2001), dado que el excedente de la producción se considera uno de los aspectos centrales para la reinversión de esos ingresos en la construcción y adecuación de las ciudades. Lo interesante de la propuesta de Castells es que reconoce las características del proceso de urbanización, pero sugiere hablar mejor de la producción social de formas espaciales, lo que tiene que ver con la aparición de la sociedad urbana, la cual desde una perspectiva antropológica se relaciona con la cultura urbana que se convierte en el centro de estudio de la naciente sociología urbana.

El avance de las ciudades norteamericanas y europeas como referente de desarrollo e industrialización que se vivió especialmente a mediados del siglo XX, también se reflejó en los procesos de urbanización en América Latina que fueron disminuyendo su intensidad con el paso de los años. Dicho proceso se caracterizó por la heterogeneidad del crecimiento, pero como plantea Macuacé (2017), tuvo un rasgo común importante que fue la expansión intensa en zonas que transitan entre lo urbano y lo rural, que entre sus variadas causas tienen el desencantamiento con la zona central y la vulnerabilidad social y la pobreza a la que está asociada.

Cambios que empezaron a consolidar asentamientos humanos marginales que 
terminaron siendo un proceso lento de transición o acomodación gradual a lo urbano, un "crecimiento acelerado y habitualmente no planeado rompe con los límites que establecen las divisiones administrativas en términos de áreas, lo cual lleva al crecimiento rururbano" (Macuacé, 2017, p. 73). Por consiguiente, la transición entre el campo y la ciudad en determinados espacios se relaciona con la aparición de periferias urbanas donde aparecen actividades económicas secundarias y terciarias, que inciden notablemente en la transformación de las manifestaciones de esa ruralidad tradicional (Ruiz y Delgado, 2008). En este sentido, las transiciones de lo rururbano caracterizan nuevas manifestaciones contemporáneas de la expansión de la ciudad que no se basan únicamente en los indicadores tradicionales sobre tamaño de la localidad, densidad poblacional, dispersión 0 el tipo de actividades económicas primarias en sitios alejados de los centros metropolitanos y urbanos.

Pero la rururbanización no es un concepto que deba aislarse de un proceso más grande que es el de desconcentración urbana, como lo refiere Otero (2017), el cual se da en dos niveles: uno suburbano y otro exurbano; el primero está asociado a procesos de asentamientos periféricos donde la calidad de vida es baja, mientras que la desconcentración exurbana responde a procesos donde las clases medias y altas buscan desplazarse a lugares periféricos para fortalecer su relación con la naturaleza, mayor privacidad y tranquilidad, manteniendo intactas condiciones de vida óptimas, incluso mejorándolas; se da posterior a los suburbios y es diferente de ellos.

Pasando a otra dimensión, el estudio de la ciudad y su planificación está atravesado por el estudio del espacio como configurador de lo urbano, y de la representación e imaginarios que se crean en los sujetos que lo habitan. Es un tema trabajado desde distintas áreas de las ciencias sociales, que van desde la geografía, la arquitectura, hasta la sociología o la psicología, entre otras, por lo cual haremos un primer acercamiento a esa definición. El espacio-lugar trasciende lo físico porque se puede apropiar o desapropiar; es decir, que se interioriza la configuración urbana a partir de las relaciones y significados propios de la vida social en la ciudad. Por ello, no hay neutralidad en los lugares ni en los grupos que los habitan, sino que los pequeños procesos de apropiación tienen "sentido en el movimiento de la superación colectiva del estado de desapropiación (alienación, expropiación, enajenación y segregación del otro)" (Martínez, 2014, p. 18).

Estas consideraciones teóricas sobre el espacio y la forma en que sus habitantes lo interiorizan permiten que se pueda ver de una manera compleja y de la mano de las interacciones más allá de lo físico y lo material, lo cual también debe incorporarse para entender la forma en que se organiza y distribuye. Ahí se encuentra la conexión entre pensar el crecimiento de la ciudad no solo desde la lógica de los planos y de la arquitectura, sino detrás de los sujetos que finalmente vivirán en ella, por eso también se retoma la categoría de ordenamiento y planificación urbana.

El ordenamiento territorial tiene que ver con tres aspectos fundamentales: el qué se ha de ordenar, refiriendo la organización de los variados usos del suelo que existen en determinado territorio (residencial, agrícola, forestal, industrial, terciario, equipamientos, infraestructuras, parques o usos heredados del medio natural); el para qué, considera los objetivos de mejora de la calidad de vida y desarrollo económico que se generaliza en la mayoría de legislaciones; y el cómo, que da cuenta de los criterios del proceso de 
ordenamiento (Pujadas y Font, 1998). Frente al último punto del proceso, se destaca que el ordenamiento se relaciona con intervenciones específicas; por un lado, legislar qué está asociado con los instrumentos de ordenación; en segundo lugar, planificar a través de planes que propongan modelos territoriales a futuro; y tercero, ejecutar las estrategias de los planes con la intención de transformar la realidad.

Por su parte, para Roitman (2008) la planificación urbana está asociada al rol estatal de diseñar, administrar y mantener las ciudades, donde interviene el crecimiento de los asentamientos humanos y crea los instrumentos para organizar las dinámicas urbanas; es decir, parte de una perspectiva tradicional ligada a funciones regulatorias y burocráticas, pero si se amplía la mirada, aparecen otros actores como el sector privado y la sociedad civil, y en ese orden, los "planificadores urbanos" no se pueden reducir a simples técnicos de la burocracia política, sino que también traen implicaciones en la restructuración social y económica.

No se debe reducir este proceso a regulaciones y decretos, sino entenderlo como una actividad politizada en la que interactúan diversos intereses según sus actores, y por eso "la negociación se convierte en una estrategia esencial. Pero en la mayoría de los casos, el planificador urbano del sector estatal es visto como un técnico que debe mantenerse ajeno al juego y poder político" (Roitman, 2008, p. 1), y no se ve la relevancia de crear una alianza entre políticos, población y profesionales.

En este orden, la planificación urbana "es una actividad negociadora y mediadora del complejo sistema de relaciones que se establecen entre la administración y la comunidad, que opera en un medio social, económico y político variable a lo largo del tiempo"
(Vallmitjana, 2002, p. 4), la cual está regulada por leyes que se convierten en un plan de intervención que se materializa en proyectos. Desde la perspectiva de esta autora, es un proceso en el que deben confluir los saberes de todos los actores de una comunidad e incorporarlos al debate, lo cual apunta a ver el camino de forma eficiente y no simplemente rápida.

Los imaginarios se pueden leer desde diversas perspectivas, una de ellas es la sociocultural, como lo plantea Canclini (como se citó en Lindón, 2007), que parte por decir que lo imaginario se diferencia de las totalizaciones que anteriormente se hacían de lo empíricamente observable, donde los estudios de las ciudades se reducían a describir lo socioeconómico y objetivo, pero actualmente interesa dar cuenta de lo simbólico, de lo heterogéneo, de lo cultural y complejo de la ciudad.

En este orden, los imaginarios son diversos y no únicos, y representan la tensión entre lo objetivo y lo subjetivo, pues se estructuran con base en esos dos aspectos, por eso también dan cuenta de lo intersubjetivo, de las relaciones sociales. "Los imaginarios aparecen como un componente necesario, constantemente presentado en la interacción social y refiriendo a formas de interacción no objetivables físicamente, o que sólo en forma inmediata pueden aludir a posiciones particulares en la ciudad" (Lindón, 2007, p. 92).

El imaginario no es únicamente una representación de lo simbólico de lo que ocurre, es un lugar donde también aparecen deseos, insatisfacciones y necesidad de comunicarse con otros, como decía Canclini (como se citó en Lindón, 2007), además porque la ciudad es un referente cercano y no tan alejado como la nación, de ella tenemos datos y accedemos a información cercana. Tal es el caso de lo que piensa la ciudad sobre esta zona; son 
versiones distintas las que construyen quienes viven en otras zonas centrales de sur a norte, que las que tienen los habitantes.

\section{Camino metodológico}

Con la investigación se buscó construir conocimiento a partir de los sujetos; es decir, el interés se centra en las experiencias, significados, símbolos, percepciones y demás elementos que se juegan en la interacción de los actores inmersos en un contexto específico y su manera de interpretar el mundo.

Así, el tipo de estudio fue descriptivo-interpretativo, al describir los imaginarios que los habitantes del oriente tienen sobre la planificación de ciudad, pues es a partir de las opiniones y percepciones que brindaron los pobladores que se trianguló la información con fuentes teóricas y de archivo para interpretar la realidad y construir conocimiento. En este sentido, el método elegido fue el cualitativo. El análisis fue de tipo interdisciplinar, tomando herramientas metodológicas del trabajo social, la disciplina histórica y la etnografía, con el cual se pretende analizar el desarrollo de la planeación en la ciudad en las últimas décadas, desde la perspectiva institucional, y cómo ha sido asumido e interpretado por las comunidades.

Así mismo, la triangulación de fuentes (archivos, periódicos, entrevistas a las comunidades, documentos institucionales) permitió develar los significados que se han construido sobre la ciudad y sus problemáticas desde posturas políticas, culturales y sociales diversas. Entre las técnicas de recolección de datos elegidas se encuentran la revisión documental (archivo histórico, Departamento Administrativo de Planeación Municipal, marcos normativos para el ordenamiento urbano territorial y prensa), entrevistas semiestructuradas y observación participante.
La población escogida fueron los habitantes del oriente de la ciudad, donde se encuentran informantes que el equipo de investigación conocía de forma previa, los docentes y los semilleros de investigación del programa de Trabajo Social, además contribuyó la cercanía que se tiene con los líderes, organizaciones comunitarias de base, entre otros, desde el semillero de Trabajo Social de la sede Compartir de Unicatólica.

Luego de la recolección de los datos en el trabajo de campo, se continuó con el procesamiento y la categorización de la información recogida. Hasta el mes de marzo de 2020 se realizaron 20 entrevistas semiestructuradas, con el apoyo de los estudiantes del semillero, que recogen los datos de informantes claves de los barrios Puertas del Sol, Valle Grande, Líderes, Potrero Grande, Marroquín y Compartir. También se hizo revisión documental en bases de datos y de la información de la página virtual de la Secretaría de Planeación Municipal para complementar los datos de análisis.

\section{Imaginarios versus planificación: algunos hallazgos}

Frente al proceso de consolidación de la ciudad en Cali, autores como Édgar Vásquez (2001), con su libro Historia de Cali en el siglo $X X$, refieren la llegada del Ferrocarril del Pacífico (1915) y la designación de la ciudad como capital del departamento del Valle del Cauca (1910), como primer proceso de expansión urbana, marcada también por la construcción de los servicios públicos y el transporte. El comercio y la comunicación que potenció el ferrocarril fueron claves en la llegada de población durante las primeras tres décadas del siglo XX, mientras que a mediados de siglo (1944-1967) la ciudad vivió un acelerado proceso de industrialización, expansión y migración relacionada con el desplazamiento de la 
zona industrial de la ciudad hacia el corredor Cali-Yumbo. Específicamente para las décadas de los años treinta y cincuenta, la población aumentó 5,7 veces, pues para el censo de 1964 la población nativa era solamente el 42,3\% (Vásquez, 2001).

Becerra (2014) aporta, en la línea de lo histórico, en la revisión de la poca ejecución de los planes futuros para la ciudad y plantea que a partir de la década de 1970 aparece una política ambigua de desarrollo urbano que consiste en densificar y expandir al mismo tiempo, pero debido a la prevalencia de intereses políticos, se obstaculizó el ejercicio de una verdadera planificación urbana de la ciudad, dando como resultado que los instrumentos legales se convirtieran en requisitos técnicos del orden nacional que no se aplicaron en la realidad, y que siguen siendo directrices inconclusas y desordenadas sobre el crecimiento de la ciudad.

En la actualidad la ciudad sigue creciendo y expandiéndose en las periferias de las laderas, al oriente y al sur, manteniendo el sentido de procesos de rururbanización que se dan al lado del jarillón del río Cauca, específicamente en la comuna 21 , que sumado a las demás comunas como la 13 , la 14 , la 15 y la 16, componen la distribución socioespacial del Distrito de Aguablanca, al oriente de la ciudad, caracterizado por la marginalidad social (Franco, 2020) y el desbordamiento de la segregación urbana (Uribe et al., 2017). En medio de estas características se siguen desarrollando proyectos de ordenamiento territorial y exigencias por parte de las comunidades para ser tenidas en cuenta en el destino de sus territorios, pues la forma en que los habitantes viven su espacio les da imágenes distintas que deben ser tenidas en cuenta desde la administración municipal.
"El oriente, el distrito de Aguablanca, es una zona con barrios vulnerables que, pues tiene muchos problemas sociales, económicos, poblacionales, pero dentro de todo eso, hay gente también de empuje, que le gusta trabajar y que tiene sueños y metas por cumplir". (Comunicación personal, Jimena, 8 de marzo de 2020)

Es decir, hay percepciones distintas, pues "una ciudad siempre es heterogénea, entre otras razones, porque hay muchos imaginarios que la habitan. Estos imaginarios no corresponden mecánicamente ni a condiciones de clase, ni al barrio en el que se vive, ni a otras determinaciones objetivables" (Lindón, 2007, p. 91), sino que lo cultural juega un papel importante en este fenómeno y otra serie de aspectos de la vida cotidiana; incluso en términos legales y de apropiación, la idea sobre el lugar que se ocupa en los espacios crea imaginarios con los que se perciben sus habitantes:

"Pues esto era invasiones, a punta de invasio-
nes todo el mundo llegaba y cogía su lote, se
formaban los barrios como La Fortaleza, La Pri-
mavera, y todos esos barrios de allá para acá,
El Diamante y todos esos barrios". (Comunica-
ción personal, Pedro, 3 de marzo de 2020)

La marginación estructural a la que se someten los habitantes del borde de la ciudad los lleva a autopercibirse en un lugar distinto del resto de la ciudad, en un borde donde son menos las oportunidades e históricamente han tenido que acceder a los derechos a partir de acciones de hecho y procesos informales que luego fue incorporando la administración, como políticas de viviendas de interés social o legalización de predios:

"Pues el barrio donde yo estoy ubicada fue un barrio que se dio por mejoramientos de vivienda, por reubicación, y en el barrio donde yo vivo, dieron lotes y pues la gente tenía que 
empezar a construir, veníamos de otras zonas de la ciudad, zonas que tuvieron que ser desalojadas por riesgos, como la orilla del río, por riesgos que tienen que ver con el tema del río; entonces, dieron lotes y pues, básicamente, entregaron con todos los servicios: agua, teléfono, energía y gas, poco a poco, líneas y redes de Internet y todo eso, y pues, básicamente, ha tenido un crecimiento". (Comunicación personal, Jimena, 8 de marzo de 2020)

Estos procesos a su vez producen prácticas y discursos, representaciones en lo psicológico, social, cultural y simbólico, "de manera individual o colectiva (esta se da en la interacción), uso y apropiación de cualquier espacio, conjunto de imágenes que se interiorizan y se configuran en la base de la cual se mira, clasifica y ordena" (Reyes-Guarnizo, 2014, p. 7); es decir, las imágenes van creando otras ideas del espacio con el fin de encasiIlarlo y delimitarlo; estar en el oriente es estar en una periferia olvidada, un lugar de deficiencia constante donde se ve difusa la figura estatal y el ejercicio pleno de la planificación:

"iAh no! a ellos les interesa gobernar, ellos prometen y no cumplen nada, eso es perder tiempo; por ejemplo, aquí en Llano Verde, ese puesto de salud que tienen ahí, eso ahí, está cerrado, eso no lo abren para nada, ¿entonces, la gente qué gana con eso?, no son sino promesas, yo por eso no participo en nada de esas vainas". (Comunicación personal, Pedro, 3 de marzo de 2020)

Aquí aparece un factor importante para pensar los imaginarios y su distancia del proceso material de organizar la ciudad, los habitantes y los actores institucionales viven y perciben la ciudad de manera distinta, se encuentran y experimentan tensiones, y estos procesos se reflejan en la manera en que la ciudad está construida y la forma en que se sigue pensando en su expansión futura, una donde las voces de los ciudadanos son escuchadas en ciertos espacios de democracia representativa pero hay un abismo en lo que finalmente ocurre en el barrio, pues las decisiones finales las toman desde la burocracia y los gremios de interés:
"Pues sí, he participado en los planes de desa- rrollo de las ciudades, se realiza cada 4 años, esos planes de desarrollo se hacen en víspe- ra de las necesidades que tiene la ciudad, de acuerdo a la problemática que presente; en- tonces, se montan unos planes que posible- mente pueden ayudar a solucionar dicha pro- blemática, sé que antes se reunía el alcalde con concejales, y lo hacían, y ahora hay más participación de la comunidad, se hace por comunas, se hace el de la ciudad general, hay participación de toda la gente que quiera par- ticipar, y también de organizaciones que quie- ran hacer parte de la organización, y, pues, considero que es más dinámico así, porque to- dos podemos aportar un poquito para el plan de desarrollo, que mejoraría las condiciones de nuestra ciudad". (Comunicación personal, Jimena, 8 de marzo de 2020)

Esto lleva a pensar en los retos de poner en diálogo y hacer efectivos en la legislación de la ciudad los imaginarios de los habitantes, sobre todo los de la periferia, que se encuentran en un lugar de vulnerabilidad y marginación histórica, pues el desarrollo de la ciudad debe ser fruto de una planificación justificada y del estudio consciente de las condiciones físicas, sociales y culturales y no solo desde soluciones generales que homogeneizan los espacios y las experiencias que en ellos se tienen.

Lo anterior es un referente para analizar la realidad del oriente de la ciudad de Cali, pues la concepción que se tiene de esta zona es que está poblada por sujetos y poblaciones desplazadas a causa de la violencia en Colombia; además, que dichas personas cuentan con condiciones tales como vulnerabilidad económica, discriminación y exclusión. La construcción de los barrios se ha 
desarrollado a través de dinámicas de asentamientos humanos que posibilitaron la fundación y el crecimiento de estos. Cabe aclarar que, por medio de la participación de sus fundadores es que dichos barrios hoy en día tienen lugar en el territo rio, teniendo en cuenta que la intervención y la planificación del Estado ha sido casi nula.

El oriente de Cali se caracteriza por ser un territorio diverso y multicultural, habitado por personas en su mayoría descendientes de indígenas y afrocolombianos. Lo anterior sitúa entonces al oriente como una mezcla potencial en cultura, etnia y desarrollo urbanístico. Se puede inferir que algunos habitantes conforman la mano de obra para las diferentes empresas de Cali y sus alrededores. Así mismo, se debe manifestar que en el oriente de la ciudad se llevan actividades como la siembra y la ganadería, lo que además da un sentido de rururbanidad a la periferia, por eso es un lugar que aporta a la economía departamental y dinamiza procesos para el consumo alimentario.

Esto da cuenta de la diferencia de imaginarios que existen entre los habitantes del sector y los que escriben y ejecutan los programas de ordenamiento, pues a pesar de ser ciudadanos con los mismos derechos para habitar la ciudad, son desconocidos y estigmatizados; por ende, quedan por fuera de la negociación y de las decisiones del uso del suelo urbano. Los imaginarios son las ideas y símbolos acerca del espacio habitado, una construcción entre lo físico y lo vivido, que se manifiesta en las formas de ser y de estar en el territorio; la gente cree en un estilo de vida presente y futuro para su barrio y su comuna, y estas ideas no entran en diálogo con las oficinas de planeación, donde los planos de megaobras y renovación urbana ven edificaciones más que personas.
El desarrollo y la construcción de estos barrios de la ciudad no son iguales a los de otras zonas, pues mientras la parte central y alrededores de la ciudad han contado con la planificación de constructoras para la edificación de los barrios, posibilitando espacio público y zonas verdes para la recreación de sus habitantes, además del equipamiento básico, las periferias del oriente han emergido en medio de la informalidad, sin planificación y sin orden, dado que es muy poca la información que tienen los participantes acerca de la planificación, distribución y organización del suelo. Además, no tienen muy claro o cuentan con escasa información sobre el POT, el plan de desarrollo y la propuesta de Cali Distrito Especial. Esto, a raíz de la falta de socialización y de procesos de educación por parte de la gobernación y de la alcaldía para con sus pobladores.

Sin embargo, es importante clarificar que sumado a que no son incluidos en estos procesos de decisión, la realidad del país es que hay poca participación de los ciudadanos en los procesos y reuniones comunitarias. La mayoría reconocen a líderes y lideresas de su comunidad, los cuales trabajan por el desarrollo de sus comunas, identifican con claridad las necesidades y los aspectos por modificar de su barrio y cuidad, pero dejan que la responsabilidad recaiga en la democracia representativa, lo que dificulta exigir otras condiciones para la inclusión en el ordenamiento urbano.

\section{Conclusiones}

En primer lugar hay que señalar que la socialización de la propuesta de Cali Distrito Especial, al igual que otros procesos de planificación, como el caso de la revisión del POT, se han realizado a partir de foros informativos por comunas, donde se convoca principalmente a las Juntas de Acción Comunal (JAC) 
y a sus representantes, y aunque son espacios abiertos que se promocionan por redes sociales y demás canales de información, no asisten la mayoría de habitantes. Además, estos espacios ya llevan las conclusiones del proceso que previamente han sido debatidos y definidos en reuniones con la academia, los representantes del gobierno, entes privados y actores empresariales, que son los que toman las decisiones sobre el ordenamiento.

Se puede decir que la mayoría de los habitantes entrevistados no conocen en concreto en qué consiste ese nuevo ordenamiento para la ciudad, ni tampoco tienen claro cuál es el objetivo de la planificación urbana, a pesar de que son conscientes de las necesidades de sus espacios cercanos y del lugar que habitan, pero sus ideas y propuestas no se corresponden con la ejecución de la política que hace la alcaldía.

Se identifica en un primer momento que hay una brecha entre los habitantes de la ciudad y quienes planean y ordenan el territorio, lo que implica tener en cuenta los variados niveles en que participa cada uno de los actores, donde las decisiones finales no son un proceso con los habitantes, sino de los actores económicos y políticos de la región. De todas formas, los informantes reconocen la necesidad de enterarse de los procesos y apoyarse en los líderes comunitarios que participan de algunos de estos espacios.

Es necesario que los proyectos de renovación urbana y los procesos de ejecución de la planificación de la ciudad se conviertan en iniciativas de negociación y participación de todos los actores implicados, que tanto los gremios como los entes gubernamentales y los ciudadanos que habitan el oriente puedan sentarse a discutir hacia dónde va la ciudad, que expongan sus particularidades e intereses, y sobre ellos se llegue a consensos para lograr soluciones que beneficien a la mayoría de ciudadanos; este es el camino más adecuado para hacer de los imaginarios una realidad, acorde con los proyectos de ordenamiento.

\section{Referencias}

Becerra, L. (2014). Transformación urbana del área de expansión de Cali. Estudio de caso: corredor Cali-Jamundí 2000-2013 (Tesis de pregrado). Universidad Colegio Mayor de Nuestra Señora del Rosario, Bogotá.

Carvajal, A. (2006). Elementos de investigación social aplicada. Cuadernos de Cooperación para el Desarrollo, (1), 29-65.

Franco, A. M. (2020). The production of marginality. Paradoxes of urban planning and housing policies in Cali, Colombia (Tesis de Doctorado). https:// doi.org/ 10.17863/ CAM.50138

García, D. A. (2015). Orientación de planificación urbana para la integración urbanística y el manejo de la segregación socio-espacial de Cali. Tesis de Maestría, Universidad Javeriana Cali. https:// repository.javeriana.edu.co/ handle/ 10554/ 16860

Hernández, M. J. (2015). Diseño de espacios urbanos desde el imaginario y la participación del ciudadano. Revista de Urbanismo, 32, 87-101.

Hiernaux, D. (2007). Los imaginarios urbanos: de la teoría y los aterrizajes en los estudios urbanos. Eure, XXXIII(99), 17-30. 
Lindón, A. (2007). Diálogo con Néstor García Canclini. ¿Qué son los imaginarios y cómo actúan en la ciudad? Eure, XXXIII(99), 89-99.

Macuacé, R. (2017). Del crecimiento urbano al rur-urbano. Universidad del Cauca.

Martínez E. (2014). Configuración urbana, habitar y apropiación del espacio. XIII Coloquio Internacional de Geocrítica. El control del espacio y los espacios de control. Barcelona, 5-10 de mayo de 2014. http:// www.ub.edu/ geocrit/ coloquio2014/Emilio\%20Martinez. pdf

Ocampo, A. M. (2017). Crecimiento urbano y planificación territorial en la ciudad de Cali. Evolución 1990-2010 (Tesis de Doctorado). Universidad de Barcelona.

Otero, R. (2017). Sociología e historia de la ciudad desconcentrada. Centro de Investigaciones Sociológicas (CIS).

Pujadas, R. y Font, J. (1998). Ordenación y planificación territorial. Síntesis.

Reyes-Guarnizo, A. B. (2014). De los imaginarios colectivos a la apropiación del territorio: un recorrido conceptual. Revista Bitácora Urbano Territorial, 24(1), 1-21.

Roitman, S. (2008). Planificación urbana y actores sociales intervinientes: el desarrollo de urbanizaciones cerradas. Scripta Nova, XII, 270(54), 1-16. https:// revistes.ub.edu/index.php/ScriptaNova/ article/ view/ 1479

Ruiz, N. y Delgado, J. (2008). Territorio y nuevas ruralidades: un recorrido teórico sobre las transformaciones de la relación campo-ciudad. Eure, 34(102), 77-95. http://dx.doi. org/ 10.4067/ S0250-71612008000200005

Susser, I. (2001). La sociología urbana de Manuel Castells. Alianza Editorial.

Uribe, H., Ayala, G. y Holguín, C. J. (2017). Ciudad desbordada. Asentamientos informales en Santiago de Cali, Colombia. Universidad Autónoma de Occidente.
Vallmitjana, M. (2002). La planificación urbana en situaciones de urgencia social: las zonas de barrios. Revista Venezolana de Economía y Ciencias Sociales, 8(3), 119-129.

Vásquez, E. (2001). Historia de Cali en el siglo XX. Artes Gráficas del Valle.

Vivas, H. (2013). Persistencia de la segregación residencial y composición del capital humano por barrios en la ciudad de Cali. Ensayos sobre Política Económica, 31(70), 122-155. Edición especial sobre economía de las ciudades. http:// www.scielo.org.co/pdf/espe/ v31nspe70/v31n70a4.pdf 